\title{
The COVID-19 Pandemic Has Stimulated Modernization of the Urboecodiagnostics
}

\author{
V. V.Chernaya ${ }^{1, *}$, B. I.Kochurov ${ }^{2}$, O. V.Bakovetckaya ${ }^{1}$, E. I.Mishnina ${ }^{3}$, \\ R. M.Voronin ${ }^{1}$ \\ ${ }^{I}$ RSMU of the Ministry of Health of the Russian Federation, Ryazan,Russia \\ ${ }^{2}$ Institute of Geography, Russian Academy of Sciences, Moscow, Russia \\ ${ }^{3}$ Ryazan State University named after S.A. Yesenin, Ryazan,Russia \\ *Corresponding author.Email: harmony19721911@gmail.com
}

\begin{abstract}
The aims of our researches is to identify priority directions of the world's cities emerging from the post-Covid crisis based on an assessment of the Russian cities environment quality before the COVID-19 pandemic. The analysis of the Russian cities ecological sustainability by the beginning of the pandemic COVID-19, component-by-component and complex assessment of quality of the Russian cities environment are done. The urgent need of the existing urboecodiagnostics system changes is explained. Directions of its efficiency and of the objectivity increasing are indicated. The needs of priority steps of development and organization for the post-Covid cities recovery after the socio-ecological crisis are justified. We resumed that there is an objective problem in integrated assessment of the urban environment quality. The novelty is: it is shown that the only integral, systemic vision of natural, anthropogenic and urban processes, the latest technologies can become the drivers of sustainable urban development.
\end{abstract}

Keywords: urboecodiagnostics, urban environment, noosphere, artificial intelligence, pandemic.

\section{INTRODUCTION}

At present, humanity is entering to completely new stage in its history, when only common, focused efforts will open perspectives for the civilization further development. In the 20th year of the 21 st century, cities found itself in a situation that has yet to be understood: dramatic changes in everyday life, isolation, new technologies of the on-line meetings, lockdowns and emptiness of the local free spaces. The future has proved difficult to predict and the present uncomfortable and unusual. The emphasis for a Healthy Recovery has never been stronger.

In spring 2020, air pollution levels in cities around the world declined to levels not seen before for tenths years. Some people breathed clean air for the first times in their lives. But pollution quickly spiked once economies began reopening, signaling a greater need for a sustainable, long-term solution.

The focus on health restoring has never been stronger. In 2020, air pollution levels in cities around the world have fallen to levels not seen in decades. Some people were breathing clean air for the first time in their lives. But pollution quickly increased as the economy began to reopen, signaling a greater need for a sustainable, long-term solution.

Today, people are faced with long-standing problems, risks and dangers, regardless of whether they live in mega policies or in small cities, in Europe or in America. Humanity will have to use all its intellectual strength to find the ways to overcome the existing and possible future crises, to recognize a new era, foreseen at the beginning of the 20th century by academician V. I. Vernadsky. There is a formation of the new complex of technological and natural processes and the transition to progressive ecological and economic, noospheric development. Previously misunderstood scientific ideas and achievements in the field of natural science, in the second decade of the 21 st century came to the main plane, showing in practice how deep and comprehensive the connection between man and nature is.

There have been several major outbreaks of new viral diseases in recent decades, including Hendra, Nipah, Marburg, and Ebola virus diseases, severe acute respiratory syndrome (SARS), and Middle East respiratory syndrome (MERS), [1]. 
The world cities were not prepared to the SARS$\mathrm{CoV}-2$ pandemic challenges. The reaction of many was late and ineffective. The virus SARS-CoV-2 broke out at an "ideal" time for it: more than half of the world's population lives in cities, in large agglomerations, moves massively over long distances and actively contact with wildlife. In such conditions, the spread of new zoonotic pathogens is inevitable for the different regions of the world.

Since the beginning of the pandemic from February 8, 2020 in Russia it is officially registered (stop coronavirus. RF) 3,983,197 cases of COVID-19, died 75 828 people. Economic and social shocks have had destructive impact to the most countries of the world. The pandemic and the quarantine limits were as hard and massive shock to the world economy, health and the entire social sphere [2]. Consequences of the disease caused by the coronavirus of severe acute respiratory syndrome-2 (SARS-CoV-2), the so-called "covid tail", (shortness of breath, rapid heartbeat, chronic fatigue syndrome) require long-term rehabilitation [3]. Forced long-term stay at home without the ability to go out led to a sedentary lifestyle and a deterioration in the mental health of citizens [4].

It can be argued that the pandemic COVID-19 is a long-overdue crisis of the structure and organization of human space - the world crisis of modern cities.

The aims are to identify priority directions and trajectories of the world's cities emerging from the postcovid crisis based on an assessment of the Russian cities environment quality before the COVID-19 pandemic.

\section{MATERIALS AND METHODS}

The data bases from international analytical observations, a number of federal and regional statistical reports were studied, analyzed and systematized. Screening evaluation of the analytical information, identification and generalization of the problems in the existing cities` ecodiagnostics were done. It is proposed to use the Artificial Intelligence (AI) technology to work with data bases and to separate useful information from them. For example, forecasting of air pollution based on data about the actual pollution of the surface layer of atmospheric air, on road traffic flow, direction and wind strength, rainfall, temperature, assessment of weather conditions and accounting for adverse meteorological phenomena, etc. The Systemic analysis allowed us to synthesize conclusions and recommendations, to predict the directions of our researches development.

\section{RESULTS}

\subsection{The World cities before the pandemic COVID-19}

The rapid urbanization of the second half of the 20th - early 21 st century increased anthropogenic pressure on nature and human-made risks, the worsening situation with air pollution and the deficit of clean water resources. Unplanned urban growth has formed inadequate and overloaded infrastructure and services (social support and healthcare, recreation and rehabilitation, industrial and municipal waste management systems, and the transport system). The total area of the world's cities is $3 \%$ of the Earth's land area, but they gave up to $60-80 \%$ of energy consumption and $75 \%$ of carbon dioxide emissions.

Since the middle part of the last century, from December 5 to December 8, 1952, about 4,000 people died from smog in London. This London type of smog consists mainly from compounds of sulfates, aerosols and carbon dioxide. Under their influence, there was a sharp increase in the death rate from suffocation among asthmatics, people suffering from bronchial diseases [5].

According to the one of the latest urban air quality reports from 2016, $98 \%$ of cities in low- and middle income countries with more than 100000 inhabitants do not meet WHO air quality guidelines. In high-income countries, that percentage decreases to $56 \%$. In the past two years, the database - now covering 3000 cities in 103 countries - has nearly doubled, with more cities measuring air pollution levels and recognizing the associated health impacts. As urban air quality declines, the risk of stroke, heart disease, lung cancer, and chronic and acute respiratory diseases, including asthma, increases for the people who live in them. (https://www. who. int/ phe/ health_topics /outdoorair/databases/cities/en/).

With the context of the guidelines for sustainable development, the world community approved and adopted at 2015 the 2030 agenda for sustainable development. Among the 17 global Sustainable Development Goals, two Goals have increased their relevance: GOOD HEALTH AND WELL-BEING: ensuring healthy lives and promoting the well-being for all at all ages is essential to sustainable development (SDG-3); SUSTAINABLE CITIES AND COMMUNITIES: there needs to be a future in which cities provide opportunities for all, with access to basic services, energy, housing, transportation and more (SDG-11), (www.un.org/sustainable development).

At the New Urban Agenda (HABITAT III Conference, Quito, 20 October 2016), in support of SDG-11, defines a modern vision of cities and other human settlements. Cities and human settlements "must fulfill social function, including the social and 
ecological function of land, universal access to safe and affordable drinking water a nd sanitation, as well as equal access for all to public go ods and quality services in areas such as health, education, infrastructure, mobility and transport, energy, air quality ...".

In according with Decree of the President of the Russian Federation No. 683 from December 31, 2015 "About the National Security Strategy of the Russian Federation", among the strategic national priorities of the country are: ensuring the improvement of the life quality for the all Russian citizens, the development and modernization of health care, the ecology of living systems and rational use of natural resources.

\subsection{The Russian cities ecological sustainability analysis before the pandemic COVID-19}

Hygienic situation by the results of Russian scientific researches shows us that the atmosphere air of the Russian settle places is the risky factor; there is an additional case of morbidity and mortality. During the period from 2000 to 2019 air pollution was probably due to the occurrence of 12.9 - 27 thousand additional deaths and 878 - 1771 thousand cases of diseases in the diseases classes of the respiratory organs, digestion, circulatory system, blood disease, hematopoietic organs, etc., [6]. According to the Main Geophysical Observatory named after A.I. Voeikov, the priority list of Russian cities with the highest level of atmospheric air pollution in 2019 included 18 cities (all of them are located in the Urals and the Asian part of the country) with a total number of inhabitants of 3.3 million people. Emissions of pollutants into the air from stationary sources amounted to - 17.1 million tons; from mobile sources -15.2 million tons.

The reasons of the high auto transport pressure on the cities air basin are: auto park, that does not satisfy EURO-3, 4, 5 and 6 standards; transport infrastructure and roadway quality are far from the international standards ISO 9000; management problems - green logistic absence.

The Russian cities water resources under influence by the all industries, agriculture and municipal services that discharge untreated or insufficiently treated wastewater with pollutants of varying degrees of toxicity. In the Central Federal District (CFD) is the critical ecological situation on water objects in the Vladimir, Moscow, Ryazan, Tula regions, in all of them water quality is quite often estimated as "dirty". The water quality of most water objects $(53-96 \%$ of the sampling points) at the Belgorod, Bryansk, Voronezh, Ivanovo, Kaluga, Kostroma, Lipetsk, Oryol, Ryazan, Smolensk, Tambov, Tver, Yaroslavl regions assessed as "contaminated" [7].
According to Rosstat, in 2018 the following noise levels were exceeded: in $48.9 \%$ of cases of measurements on highways and streets with heavy traffic in urban settlements; $38.4 \%$ of measurements on railway tracks passing through urban districts; $6.3 \%$ of measurements in the industrial on the border with sanitary zones; $24.8 \%$ of measurements near the existing residential buildings in urban settlements; in $16.5 \%$ of cases of measurements inside of organizations, which are located on 1-st and 2-nd floors.

The level of vibration was also high, especially when measuring on highways and streets with heavy traffic in urban settlements (in $31.6 \%$ of cases), on railway roads passing through urban districts (in $28.6 \%$ of cases), in the airports area (in $37.1 \%$ of cases).

By the results of studies and researches carried out by the Ministry of Natural Resources and Ecology of the Russian Federation in 2018 were indicated that in the period 2010 - 2018 the amount of waste generated annually almost doubled, from 3.735 million tons to 7266.1 million tons. The amount of disposed waste increased from 593.0 million tons to 1029.2 million tons, or on $73.5 \%$. As a result of the chemical polluted water migration from the territory of landfills were contaminated regional soils and water sources.

According to the energy efficiency rating, not all Russian cities provided and followed by the technical indicators:

- Reducing the energy intensity of the Gross Regional Product;

- Public sector buildings energy efficiency of;

- Street lighting and the road sector energy efficiency;

- Heat supply energy efficiency in the budget sector.

Organizational indicators - energy efficiency in construction and major repairs, promotion of energysaving lifestyle - were also provided at a low level [8].

The population of Russian modern old-explored territories and cities acquires specific environmentally dependent and ecologically determinate diseases, including chronic and pathological ones.

Population health is one of the main between indicators of sustainable development of the country. In 2018, in Russia was revealed:

- 624.709 new cases of malignancies (which is 183,988 more than in 1998). In 2018, the incidence of malignant neoplasms of urban residents amounted to 479.6 new cases per 100 thousand population [9].

In 2018, only $3.2 \%$ of Gross Domestic Product (GDP) was spent on healthcare in Russia. In 2020 - in the year of the pandemic COVID-19 the expenditures of the country's regions on health care almost doubled. 
And at the federal level, the increase was even more significant -2.2 times [10].

We have to resume that till the beginning of 2020, the ecological and social stability of Russian cities was not achieved, which ultimately led to human casualties and enormous state spending on health care and medicine. For survivors of a serious illness, defeating the SARS-CoV-2 virus is just the beginning of an unknown path to recovery. What follows buy the acute phase of SARS-CoV-2 infection depends on the spread and severity of viral attacks in different cell types and organs. Although COVID-19 is an infectious disease that primarily affects the lungs, its multi-organ damage requires an interdisciplinary approach that covers almost all branches of internal medicine and geriatrics [11].

\section{DISCUSSION}

The COVID-19 pandemic has shown how difficult it is for a weakened person to survive in grand agglomerations, with millions of automobiles, among asphalt and concrete, and with a faceless landscape. Not only architects, but also ordinary citizens are interested in a comfortable environment creation, inner-city and suburban rehabilitation infrastructure, sanitary and visual quality of "green architecture". Urban watergreen bases should serve for the people benefit and for the cities development after the pandemic, will act as effective intermediaries between nature and society.

Until the 20th century, the idea that "a true garden should satisfy all human senses: not only sight, but also hearing (from where care of birds, noisy waterfalls, Aeolian harps, garden instrumental concerts) and smell (fragrant flowers and herbs, flowering trees and bushes, the smell of flowering plants and cedar resin, filling the air with a special healthy aroma) was at the heart of landscape art [12].

COVID-19 has forced a review of the standards and norms of urban life. Environmentally and sanitaryhygienic dangerous technologies, aesthetically unattractive buildings as concrete boxes should remain in the past. A new type of city is a new approach and technology of planning and development, in which the processes of destruction of nature and the spread of infections are minimal, controlled and effectively eliminated. At the same time, the ecological-urban planning (landscape-ecological) approach allows us to solve this problem by creating a new type of cities cities after the pandemic [13]. The ecological-urban planning actualizes the cities integration into natural systems and in the creation of ecological and urban planning complexes - cultural urban landscapes that function, on the one hand, according to the laws of nature, on the other - effectively managed.

The multiplicity of environmental factors and the determination of critical values of urban-ecological characteristics still great difficulty and nowadays. It is necessary to combine the efforts of specialists and scientists from certain areas of urbanism, from socioeconomic to medical. Only systematic comprehensive analysis of the situation will allow us to find optimal directions for the development of cities after the COVID-19 pandemic.

Like the Academician V. I. Vernadsky tendencies to synthesize natural science and social science, the development of urban environmental diagnostics should go in the direction of studying the parameters of the environment, the social sphere and the state of public health. We save the hope that the overall research effort will soon bear fruits (results). For example, mashing learning (MashingLearning, ML), deep learning (DeepLearning, DL) and big data operation (Bigdata) are having an unexpectedly rapid and serious impact on society around the world [14].

Artificial Intelligence (AI) for the 21 st century is the same as electricity for the 20th and steam energy for the 19th [15]. AI technologies for diagnosis have already found their application in medicine: radiology, ophthalmology, dermatology and other areas of medicine [16]. The development of electronic medical records has made it possible to store a large amount of clinical data, which contributes to the further development of the methodology for using AI in healthcare.

In urban diagnostics, machine and deep learning will allow us to work with large amounts of data, extracting useful information from them. For example, forecasting air pollution using data on the actual pollution of the surface air layer, traffic flow, wind strength, precipitation and temperature. It can combine data from urban ecology, meteorology, transport engineering, urban architecture, hydrology, dendrology, etc.

The purpose of the learning systems developing is to extract semantic content from existing or incoming data. Thus, researches in the field of biological diversity shows changes over time for the species population. Experts can already teach the computer how to predict further population values. Let's assume that we have an incomplete set of dimensions or measures. With the help of computer training, the process of filling in and predicting data is possible, since measurements tend to move from extreme values to average values. This phenomenon can be used to the practical application of a good idea of using statistical qualities of data to estimate missing or future values. A simplified version of the machine learning process is shown in Figure 1.

The specialist gives to the system attributes and characteristics for each sample and gives the command to predict the category. If the prediction is correct, the transition to the next sample occurs, if not, the correct value is supplied. After the samples sequential cyclic 
processing, the classifier's parameters are modified, and it performs a much better job of prediction. Thus, the specialist checks the system correctness by new unfamiliar data presenting for it, and determines how accurately it is able to extract semantic content from them.

Urban transformation and trends can be understood through the critical analysis of in-depth empirical modeling. Urban density and the spread of disease, traffic pressure, water and air pollution are all important determinants of urban development [17].

The new emerging post-COVID policy in the field of combined healthcare and tourism services requires the expansion of the range of services. It also emphasizes the effective rehabilitation of the recovered people, including the greater involvement of renewable recreational resources of the natural environment. The suppliers of healthcare, tourist, preventive, and rehabilitation services are in turbulent social and economic environment affected by pandemics and epidemics. They face growing requirements in terms of equality, quality, responsiveness, effectiveness, and accessibility. The use of regional resources became a relevant and timely measure following the pandemic restrictions as well as the prohibition on cross-border movements and the consumption of services outside the regions [18]. The special significance of urban and suburban territories, protected areas and landscapes, as comfortable "green islands" in the public health system was brightly revealed.

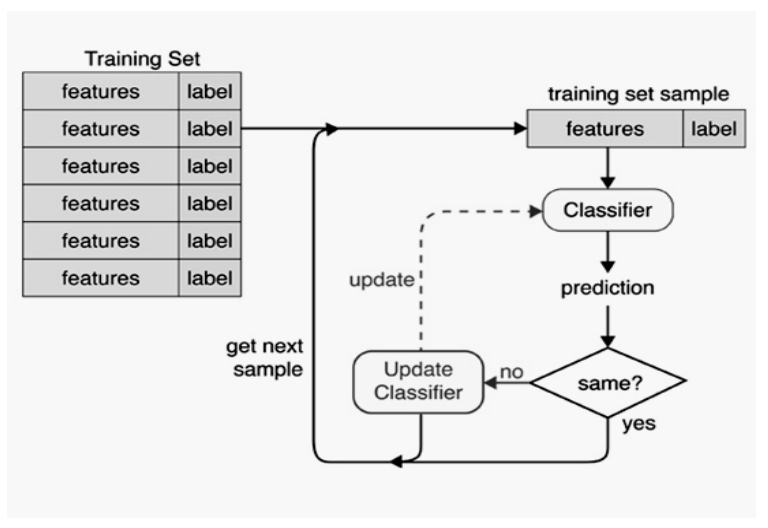

Figure 1A simplified version of the machine learning process.

As contextual megatrends of urban ecology and urban planning, we distinguish:

1. Significant changes in land usage and construction standards that allow modernization of urban construction and agriculture.

2. Implementation of the urboecodiagnostic studies and urboecomonitoring results.

3. Support innovation through such methods as mixed land use, more compact medium-rise buildings with green and water infrastructure; new types of zoning; new approaches to water-green landscapes and green space configurations.

4. Changes in the urban economy structure with the transition to a more innovative and consumer-oriented one.

5. Changes in the field of public health and rehabilitation of all the population, with an accentual use of local forest, parks and revitalized territories resources.

6. Increasing environmental friendliness, the desire of citizens to live in well-maintained and comfortable cities and districts.

7. Accounting and adapting to climate changes.

8. Technological innovations related to the design of smart cities and homes.

9. The development of environmentally less "toxic", ecological friendly types of transport.

These driving directions are just beginning to interact with the modern Russian urban system and determine the medium-term and long-term goals for urbanization.

From the result of implementation of these defining directions in the practice of developing and adopting conceptual and strategic decisions, plans and programs for urban development the health of urban residents and the sustainability of cities, the ability to overcome any challenges and pandemics will be determined.

\section{CONCLUSION}

1. Russian cities entered the pandemic COVID-19 being economically, socially and environmentally unsustainable, which led to human losses and enormous state spending on health care and medicine.

2. Science-based urban development after the pandemic COVID-19 is a strategic social and environmental task, the solution of which is economically beneficial for any state.

3. Urboecodiagnostics is a progressive direction that helps to identify real problems and improve the urban population and the urban environment.

4. The rapid increase in the number of weakened citizens and invalids requires urgent measures to improve the environment quality, its restoration and adaptation to modern and predictable challenges.

5. The priority of public health and comfort of the urban environment, increasing environmental responsibility and improving the processes of diagnosing and predicting of the urban environment quality are priorities for the cities development in the world after the pandemic. 
Academician V. I. Vernadsky believed that the time would inevitably come when humanity would need to develop a unified strategy for the development of the biosphere and new standards for organizing its lifestyle. That's the time. The invisible world of viruses has been an important factor in the evolution of urban life. Today, only a holistic, systemic vision of natural and man-made processes and the latest technologies can become the drivers of sustainable urban development.

\section{AUTHORS' CONTRIBUTIONS}

Chernaya V. V., the research concept and the article author, corrector of the final version.

Kochurov B. I., co-author of the article concept, corrector of the first version.

Bakovetckaya O. V., selection of literary sources, co-author of the article concept.

Mishnina E. I., co-author of the article, formulation and execution of conclusions.

Voronin R. M., finalized the final version of the article, correction of the references list.

\section{REFERENCES}

[1] A.T. Irving, M. Ahn, G. Goh et al., Lessons from the host defenses of bats, a unique viral reservoir. Nature, pp. 363-370 (2021). https://doi.org/10.1038/s41586-020-03128-0/.

[2] Economical results of pandemic - in the World Bank forecasts (2021). https://news.un.org/.

[3] A.W. Vaes, F.V.C. Machado, R. Meys et al., Care Dependency in Non-Hospitalized Patients with COVID-19, in: Journal of Clinical Medicine, 9 (9), (2020), p. $2946 . \quad$ DOI: https://doi.org/10.3390/jcm9092946.

[4] S. L. Cindrich et al, Associations Between Change in Outside Time Pre-and Post-COVID-19 Public Health Restrictions and Mental Health: Brief Research Report. Front, Public Health, 9, (2021), p. 61.

[5] E. S. Ivanov, B.I. Kochurov, V.V.Chernaya,Environmental resource studies, pp. 22-23 (2014).
[6] A. Yu. Popova, N. V. Zaytseva, Hygienic Assessment of Atmospheric Air Pollution Dynamics in the Russian Federation, Health Risk Analysis-2020 in conjunction with the International Meeting of Environment and Health Rise-2020 and the Round Table of Nutrition Safety, pp. 235-243 (2020).

[7] G. M. Chernogaeva et al., Overview of the environment state and pollution in the Russian Federation for 2019, 2020. https://www.meteorf.ru/ product/infomaterials/90/

[8] The Ministry of Energy of the Russian Federation. Russian Federation regions energy efficiency ranking. https://minenergo.gov.ru/

[9] The Ministry of Health of the Russian Federation (2019). https://minzdrav.gov.ru/

[10] Regions spent twice as before on health care. Kommersant(2021). https://www.kommersant.ru/

[11] Gemelli Against COVID-19 Post-Acute Care Study Group. Post-COVID-19 global health strategies: the need for an interdisciplinary approach,in: Aging ClinExp Res., 32(8), (2020), pp. 1613-1620. https://doi.org/10.1007/s40520-020-01616-X.

[12] D. S. Likhachev, Gardens poetry (2018).

[13] I. V. Ivashkina, B. I. Kochurov,Urboecodiagnostics and Moscow balanced development, p. 27 (2019).

[14] A. Glassner, Deep learning without mathematic 1, (2019), pp. 583- 584.

[15] J.Barrat, Our final invention: Artificial intelligence and the end of the human era (2013).

[16] S. Kulkarni et al., Artificial intelligence in medicine: where are we now? In: Academic radiology, 27(1), (2020), pp. 62-70. https://doi.org/ 10.1016/j.acra.2019.10.001.

[17] A. M. Salama, Coronavirus questions that will not go away: interrogating urban and socio-spatial implications of COVID-19 measures,in: Emerald Open Research, 2 (2020).

[18] V. V. Chernaya, Paulo J. Moreira, V. P. Chizhova et al., Developing rehabilitation services: Medical and ecological tourism resources for disabled people and physically challenged people in wetlands conditions of natural protected areas, in: International Journal of Healthcare Management (2021).https://doi.org/10.1080/20479700.2020.185 9779. 